\title{
REFLEXIÓN SOBRE LA VIVIENDA DE INTERÉS SOCIAL PARA LA COMUNIDAD WAYÚU
}

Pedro A. Gómez Bejarano*

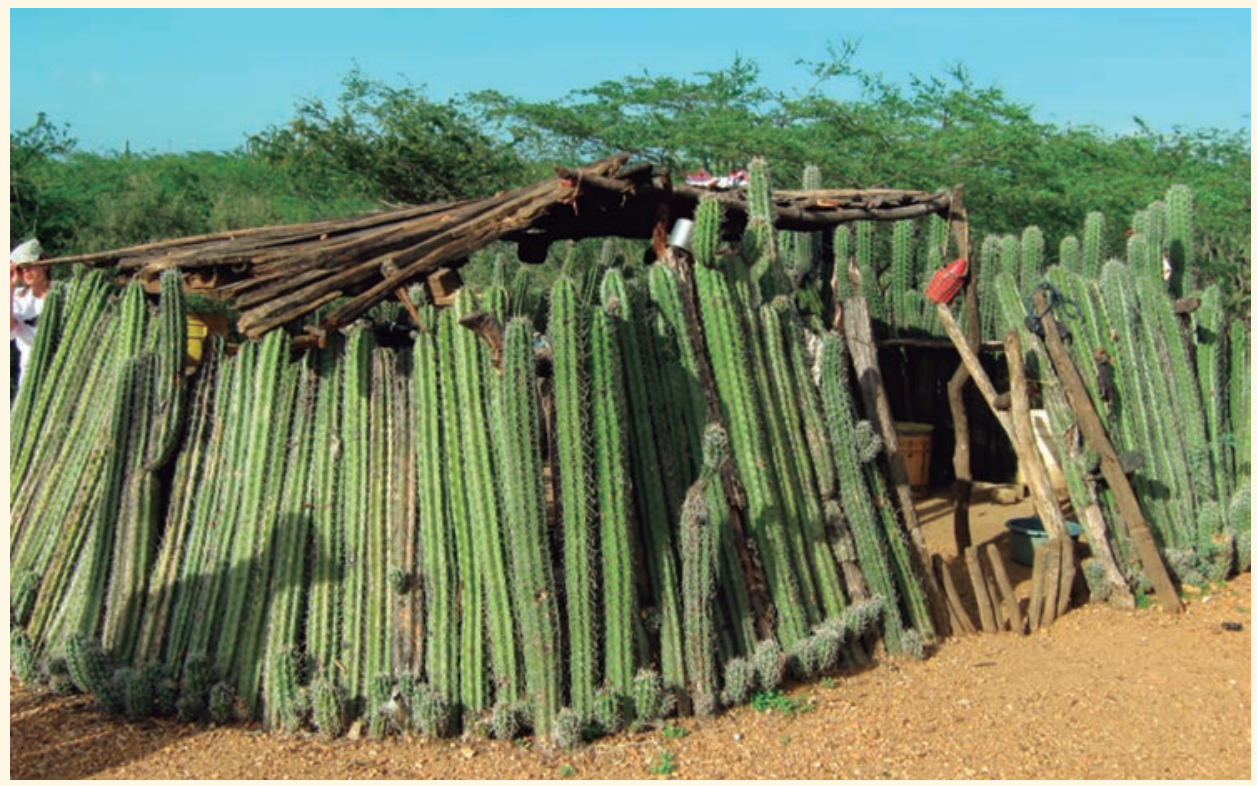

\section{RESUMEN}

En este artículo se hace una reflexión sobre la solución de vivienda para la comunidad Wayuu, población de bajos recursos asentada en la Guajira colombiana. Así, se ha identificado un problema que tiene implicaciones más profundas que el simple hecho de proponer proyectos urbanos y arquitectónicos, pues las diferentes alternativas técnicas y económicas que tienden a bajar costos van en detrimento de la calidad física, de las condiciones de habitabilidad e incluso del ser social, sin dejar a un lado la dependencia de los largos y costosos créditos. Sin duda una situación crítica que podría contrastarse si se trabaja para propiciar el desarrollo de las comunidades, a través de una explotación positiva y sostenible de la riqueza territorial del país, mediante trabajos estables y salarios dignos que generen una autonomía social para la solución de sus problemas. Seguidamente, se incluyen además las propuestas de diseño de tres grupos de estudiantes de la Facultad de Arquitectura de la Universidad Santo Tomás de Bucaramanga, presentadas en el concurso Internacional CONVIVE VI, convocado por la revista ESCALA con motivo de su versión dedicada al territorio de la comunidad Wayuu, y de las cuales una mereció la primera mención por parte del jurado.

\section{PALABRAS CLAVE:}

Vivienda de Interés Social, Comunidad Wayúu, Concurso CONVIVE VI, primera mención. 


\section{REFLECTION ON SOCIAL INTEREST HOUSING PROGRAM FOR THE WAYÚU COMMUNITY}

Pedro A. Gómez Bejarano*

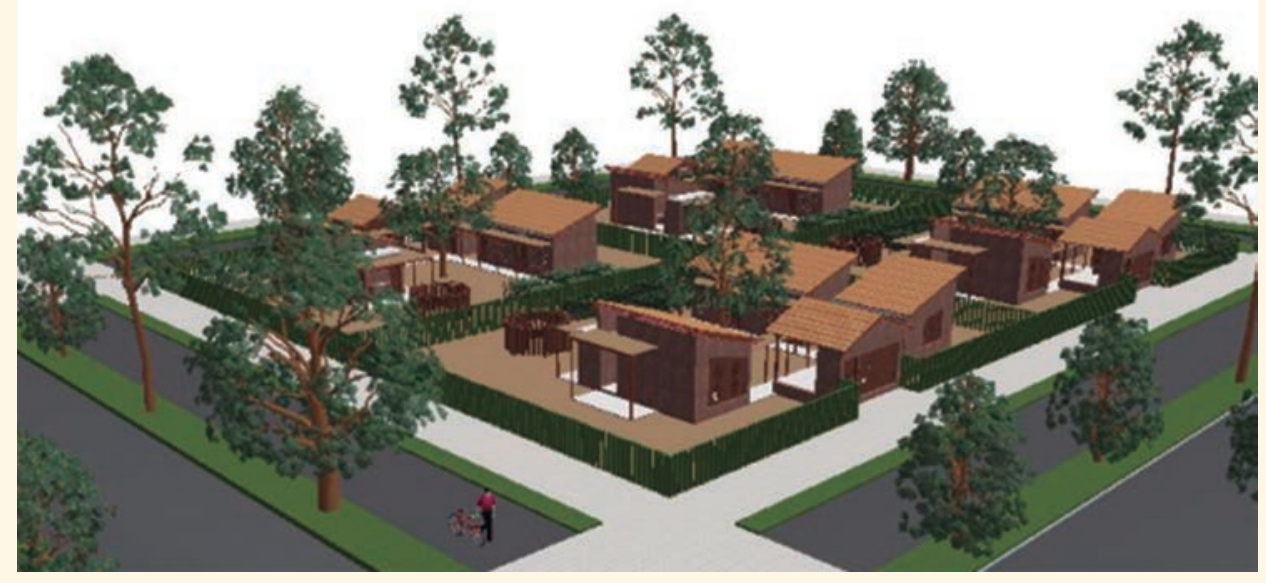

Arquitecto Universidad Nacional de Colombia. Docente en la Facultad de Arquitectura USTA Bucaramanga. Director de Taller VIII. Especialista en Gestión de la Planeación Urbana y Regional. Coordinador del Area Urbano-Ambiental de la Facultad de Arquitectura de la Universidad Santo Tomás de Bucaramanga. Coordinador de la Especialización en Gestión de la Planeación Urbana y Regional de la misma Facultad
Render o maqueta virtual de las viviendas planteadas

Fuente: Fotografía suministrada por el autor

\begin{abstract}
This article reflects on the housing solution for the Wayuu community, low income population settled in the Colombian Guajira, up north the country. Thus, it is identified a problem that has deeper implications than a simple proposal of urban and architectural projects, since the different technical and economic alternatives that tend to reduce costs drive against the physical quality of living conditions and even of social being, as well as the dependence on the long and overpriced loans. Certainly, a critical situation that could be contrasted by promoting effectively the development of communities, across a positive and sustainable exploitation of the territorial wealth of the country, supported with stable jobs and decent wages that generate social autonomy to solve their problems. Then, the article also include the projects of three students groups from the Faculty of Architecture at the University of Santo Tomas de Bucaramanga, presented at the International Competition CONVIVE VI which was organized by the magazine ESCALA on his version dedicated to the territory of the Wayuu people. One of these proposals won the Jury's First Mention.
\end{abstract}

\section{KEYWORDS:}

Social Interest Housing, The Wayuu Community, CONVIVE VI Competition, first mention 
Resolver el problema de la vivienda para comunidades indígenas, entre ellas la Wayúu, es tan complejo o más que el problema de la vivienda para grupos urbanos de bajos recursos.

En esencia es un problema económico, es un problema salarial. Se presentan en el país grandes desequilibrios económicos entre quienes sobreviven con el salario mínimo y quienes tienen grandes excedentes salariales; en los estratos altos con el excelente salario se tiene acceso al alimento, al vestido, a la educación, a la salud, a la cultura y por supuesto a la vivienda, con gran dignidad; mientras tanto, en los niveles bajos deben trabajar los dos esposos y los hijos, incluso los menores, para lograr dos o tres salarios mínimos, que aún así no logran acceso digno para suplir sus necesidades, entre ellos la vivienda, la cual en muchos casos, permanece en obra por varios años.

Las políticas de Estado, no sólo en Colombia sino en general en América Latina, parece que se preocupan más por reducir la vivienda, minimizar el espacio público y comunitario, buscar subsidios, préstamos a largo plazo, utilización de materiales más baratos (de regular calidad, hasta de reciclaje) y otras búsquedas como terrenos no bien localizados, con riesgos, para bajar el precio de la vivienda, cuando se sabe que todo radica en el problema económico.

Por supuesto, resolver el problema de la vivienda rural y urbana, para comunidades como la Wayúu, llevan a pensar cómo lograr soluciones con el recurso existente, en este caso el trupillo, yotojoro y otras especies nativas, barro, pisos en tierra, con procedimientos artesanales primitivos, que ya los nativos han aplicado por años y años, con su capacidad de adaptación al clima y vivir de lo que naturaleza les brinda, en medio de la escasez de agua potable, problema de grandes dimensiones, o sortear las inundaciones en las épocas de grandes lluvias, soluciones de alcantarillado o disposición de aguas negras. Por otro lado, el municipio de Uribia con su riqueza marina, su potencial energético solar y eólico, riquezas mineras como el carbón, gas natural, sal marina, podría resolver sus necesidades si esos recursos quedaran realmente en el Departamento y en el Municipio.

Es extraño saber que desde hace más de veinte años se explotan las minas del Cerrejón, que implicó el desplazamiento de población hacia el casco urbano de Uribia, con grandes ingresos para el Departamento y el Municipio a pesar de los bajos porcentajes de las regalías, y hoy todavía no se ha resuelto ni el acueducto, ni el alcantarillado y menos la vivienda, ni en el área urbana, ni en su perímetro actual, menos en las áreas rurales; al interior de las instalaciones del Cerrejón hay agua potable y energía eléctrica producto de la fuerza eólica, los Wayúu no la tienen.

Buscar soluciones postmineras, tal como se plantea en las bases del concurso Convive $\mathrm{VI}$, cuando se sabe que habrá carbón por cien años más, es contradictorio; precisamente es ahora que hay que utilizar esa coyuntura de explotación, así como se propone aprovechar los recursos costeros (pesca, turismo, puertos, centros de acopio), la ganadería caprina (curtiembres, por ejemplo), superar la explotación artesanal de la sal marina, potabilizar agua marina y/o subterránea, para lo cual la tecnología existe (molinos de viento para extraer e impulsar el agua, plantas de tratamiento), potenciar el cultivo de especies del lugar (sábila, melón, patilla, fríjol, papaya, cacao, por ejemplo) pero que requieren agua, que significa regadío, incluso llevar agua desde la baja y media Guajira por medio de un posible ferrocarril cisterna, de un acueducto impulsado por energía eólica; apertura de vías de comunicación, es decir las infraestructuras necesarias, para hacer posible que dichos recursos bien explotados y manejados, se vean reflejados en un mejor nivel de vida, tanto rural como urbana, con vivienda digna, ciudad digna, vida digna. 
¿Porqué no se habla de problema de vivienda para las clases medias (que mal que bien con esfuerzo se tiene acceso a élla), y menos se habla de problema de vivienda para la clase alta que lo resuelve con sus propios recursos o préstamos fáciles de pagar? ¿Cuándo se dejará de hablar de problema de vivienda para la población de escasos recursos, de préstamos a largos plazos, de subsidios y pseudo vivienda? Mientras la vivienda sea mercancía y haya especulación con el suelo suburbano y urbano, el derecho a la vivienda digna, reconocido por la Constitución Colombiana, no será posible sino cuando cambien estas condiciones.

\section{Concurso Internacional Universitario de Hábitat Convive VI. Comu- nidades indígenas, economía post-minera y urbanismo sostenible: Uribia 2050.* Primera mención}

*Con el apoyo de: Gobernación de la Guajira, Alcaldía de Uribia, ONU hábitat, PNUD, PMA, OPS, Cerrejón, Colegio de Arquitectos de Venezuela, Colegio de Arquitectos del Ecuador, y Revista Escala, SCA, ACFA, Metrovivienda, Consejo Profesional Nacional de Arquitectos.

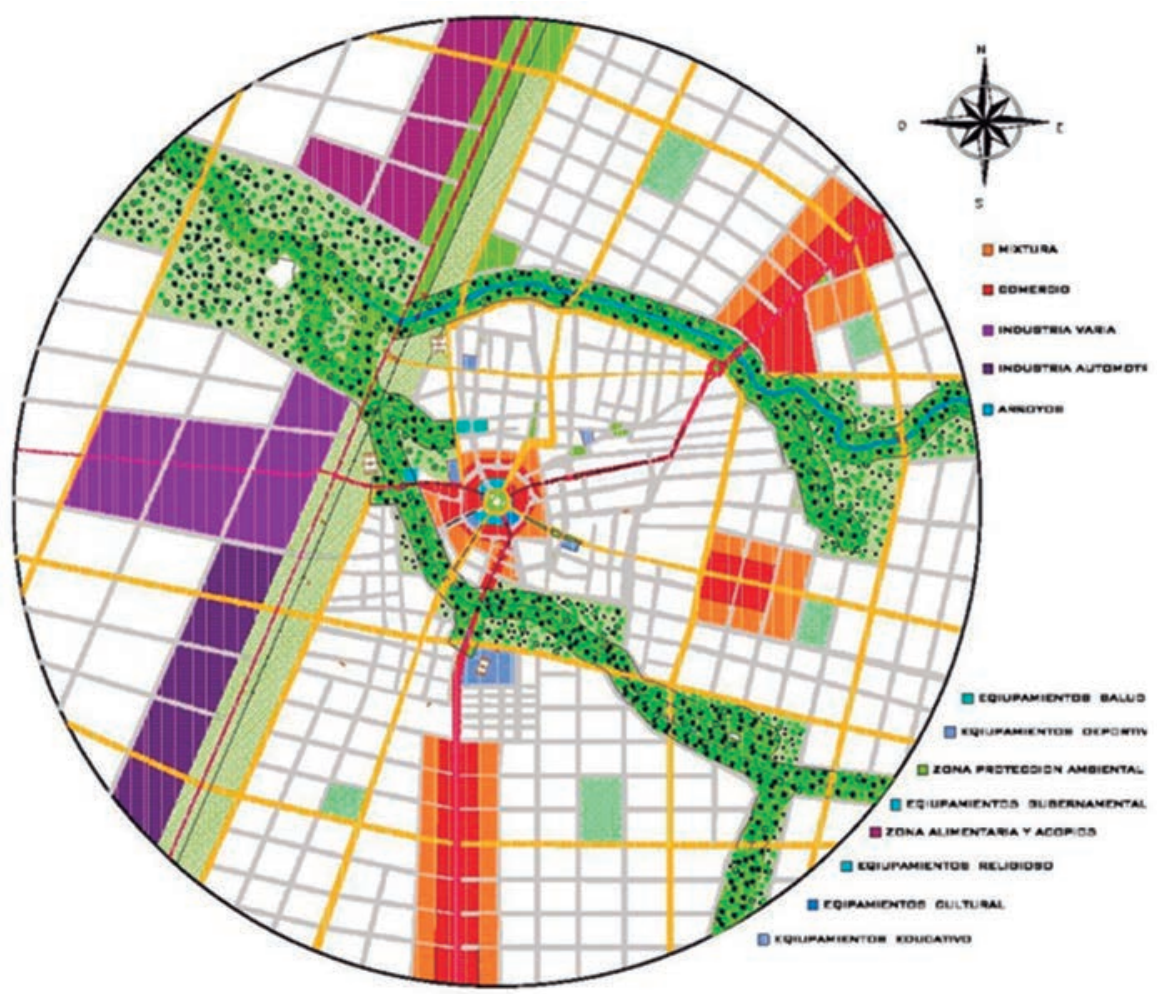

En el marco del Concurso Universitario de Hábitat CONVIVE VI de 20I I, versión internacional, con la participación de Ecuador, Venezuela y Colombia, para plantear soluciones de vivienda de interés social en la Guajira, la Facultad de Arquitectura de la Universidad Santo Tomás Bucaramanga, participó con tres grupos de estudiantes de $8^{\circ}$ y $9^{\circ}$ semestres, con la obtención de la la Mención de Honor, por parte de una de los tres propuestas presentadas, de entre 49 proyectos y 24 facultades de Arquitectura; de estas se preseleccionaron 48, de los cuales se seleccionaron II, y se premiaron $5: 1^{\circ}, 2^{\circ}$ y 3 er puestos, $I^{\mathrm{a}}$ mención y $2^{\mathrm{a}}$ mención.

Los estudiantes participantes en el grupo que obtuvo la primera mención fueron, Andreina Builes Torres, Gina Paola Camargo, Diana Carolina Padilla, estudiantes de octavo semestre y Olfer Meneses, estudiante de noveno semestre.
Propuesta urbana planteada. Primera Mención Plano I

Fuente: Grupo de estudiantes USTA 
El segundo grupo estuvo conformado por Mayra Andrea Cepeda, Yexabel Calderón y Wilson Guerrero, todos estudiantes de octavo semestre.

El tercer grupo lo conformaron Claudia Victoria Gambá de octavo semestre y María Fernanda Martínez y Camilo Corredor, estudiantes de noveno semestre.

Los equipos de trabajo arriba señalados contaron con la asesoría de los docentes de la Facultad de Arquitectura USTA Bucaramanga, Hernando René Ladino B., arquitecto de la Universidad Nacional de Colombia, quien es el director del Taller IX, y Saúl Rugeles Quiroz, arquitecto de la Universidad Nacional de Colombia, director del taller VI.

La estudiante Cira Elena Navas García, perteneciente a la comunidad Wayúu, y alumna de IV semestre de la Facultad de Derecho de la USTA de Bucaramanga apoyó y acompañó a los grupos de trabajo de la Santo Tomás en la visita de campo realizada previamente al proceso de diseño.

\section{LAS BASES DEL CONCURSO}

El concurso se organizó con el propósito de generar reflexiones sobre la arquitectura, el diseño urbano, el manejo ambiental y ecourbanístico, de conjuntos de vivienda para los sectores sociales de bajos ingresos, dentro del "Plan Fronteras para la Prosperidad", acorde con la política de beneficios a las diferentes comunidades, en las que se reconoce el nivel de desarrollo menor en las zonas de frontera del país, entre ellas la Guajira con sus límites con Venezuela, hábitat del grupo social indígena Wayúu; con altas necesidades básicas insatisfechas, con el impacto de la explotación minera y la política sobre regalías, como recursos para acceder a los servicios de agua potable, alcantarillado, salud, educación y reducción de la mortalidad infantil, teniendo en cuenta su realidad cultural, sus dinámicas sociales, necesidades, aspiraciones, problemas, conflictos, fortalezas, debilidades, el plan de vida Wayúu y el plan de salvaguarda de su cultura, como también la interdisciplinariedad, la factibilidad y la pertinencia.

El objetivo: proyectar una visión prospectiva para el año 2050, multiescalar (vivienda, ranchería, territorio indígena, municipio, departamento, península de la Guajira, plurietnia -indígenas, mestizos, blancos, afrodescendientes-), para el municipio de Uribia, capital indígena de Colombia.

Preveer el crecimiento municipal, con base en el Plan de Vida Wayúu, que articule armónicamente estos principios con las estrategias de desarrollo Departamental y el Plan Básico de Ordenamiento Territorial, con proyección al futuro, y aprovechamiento eficientemente los recursos naturales y económicos disponibles, sin poner en riesgo la identidad cultural Wayúu, a partir del reconocimiento de su riqueza cultural, sus prácticas espaciales y técnicas tradicionales. Dentro de este marco general, proponer un plan de mejoramiento del espacio público actual en el casco urbano de Uribia, un plan de vivienda nueva y un plan de espacio público y de equipamientos urbanos para el área de expansión urbana en un área de 12.5 hectáreas. Se considera como límite, entre el casco urbano y la zona rural para el 2050, un círculo con radio de $2.5 \mathrm{Km}$., cuyo centro es el obelisco del parque central del casco urbano actual.

Tener en cuenta para pensar el futuro del municipio, tres aspectos:

I. El cultural (comunidades indígenas y mestizaje, blancos, afrodescendientes; modo de vida Wayúu). 
2. El económico (la no dependencia minera), con el aprovechamiento de los recursos y sus potenciales.

3. El medio ambiente de ese entorno biofísico semidesértico que caracteriza a la alta Guajira, que es el territorio Wayúu.

Es a partir de estos tres aspectos entrelazados armónicamente, que se pueden establecer tanto el modelo como los proyectos más estratégicos en esa visión de futuro posible y deseado.

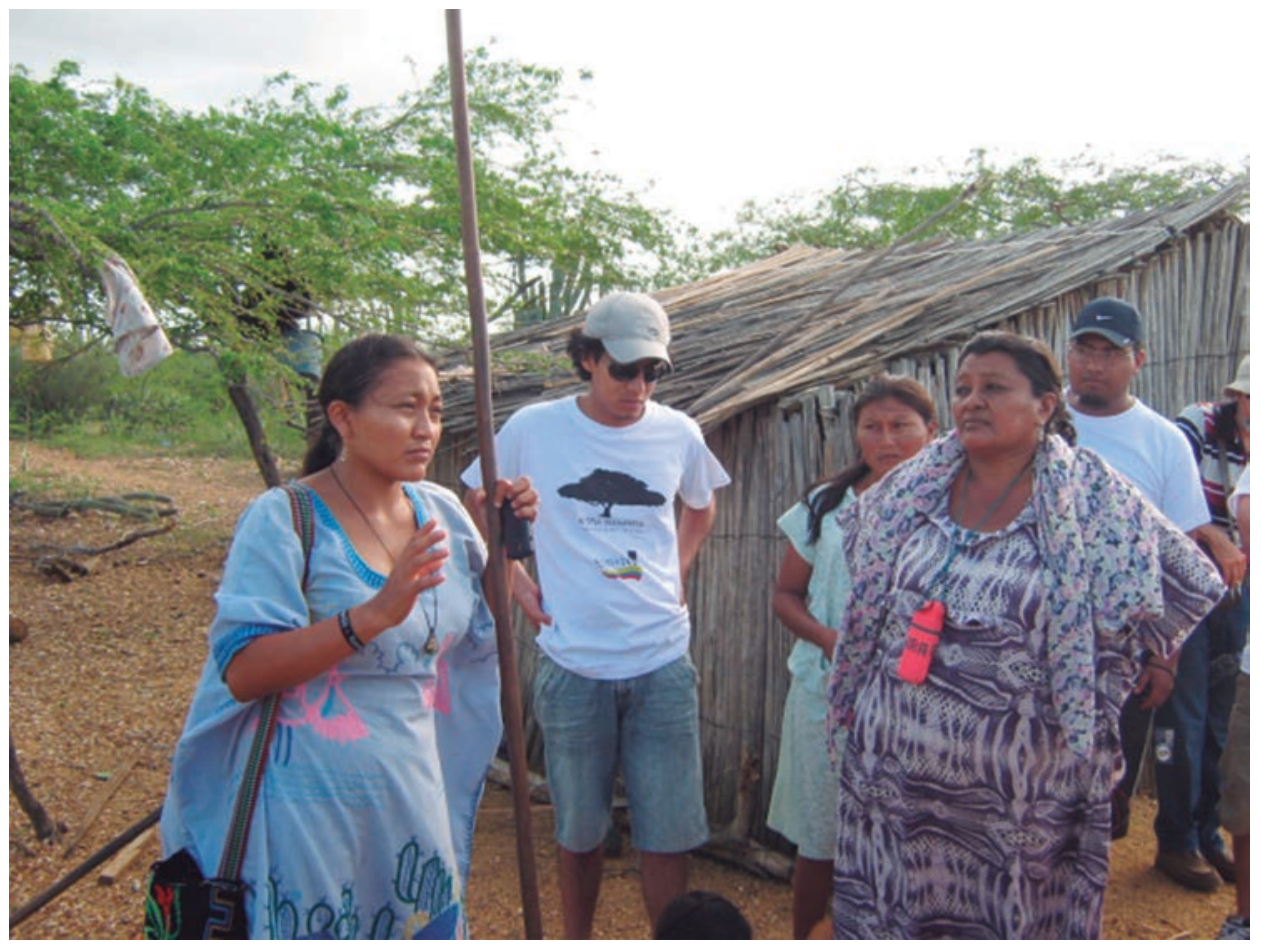

El aspecto cultural, se expresa esencialmente en el modo de vida Wayúu y su cosmogonía, organizado en veintidós clanes familiares territoriales, con gran sentido de libertad, en un territorio que ocupa la alta Guajira (todo el municipio de Uribia) y va hasta el golfo de Maracaibo en Venezuela; la frontera colombo-venezolana para esta comunidad no existe, sólo existe la comunidad Wayúu y el territorio que siempre ha ocupado.

Estos clanes se organizan en rancherías, alejadas unas de otras; cada una compuesta por 10 a 20 viviendas también separadas a distancias más cortas.

Su organización social se basa en un conjunto de normas propio de este pueblo seminómada, que está en movimiento libre por el territorio, en busca de alimento para sus rebaños caprinos; son clanes matriciales, en los que el tío materno (hermano de la esposa) es la máxima autoridad, y establecen su territorialidad a través de sus cementerios. Los palabreros o Pütchipü'üi son como los intermediarios entre conflictos, responsables de mantener el equilibrio entre los mandatos ancestrales y el orden universal; se honran la palabra, el diálogo y la persuasión, como forma pacífica de dirimir conflictos y garantizar la paz.
Fotografia I Visita a una familia Wayúu. En la imagen la estudiante Cira Elena Navas García, y miembros de la comunidad Wayú

Fuente: Fotografía del autor 
fotografía 2 Escultura de un palabrero. Casa Cultural Uribia

Fuente: fotografía del autor

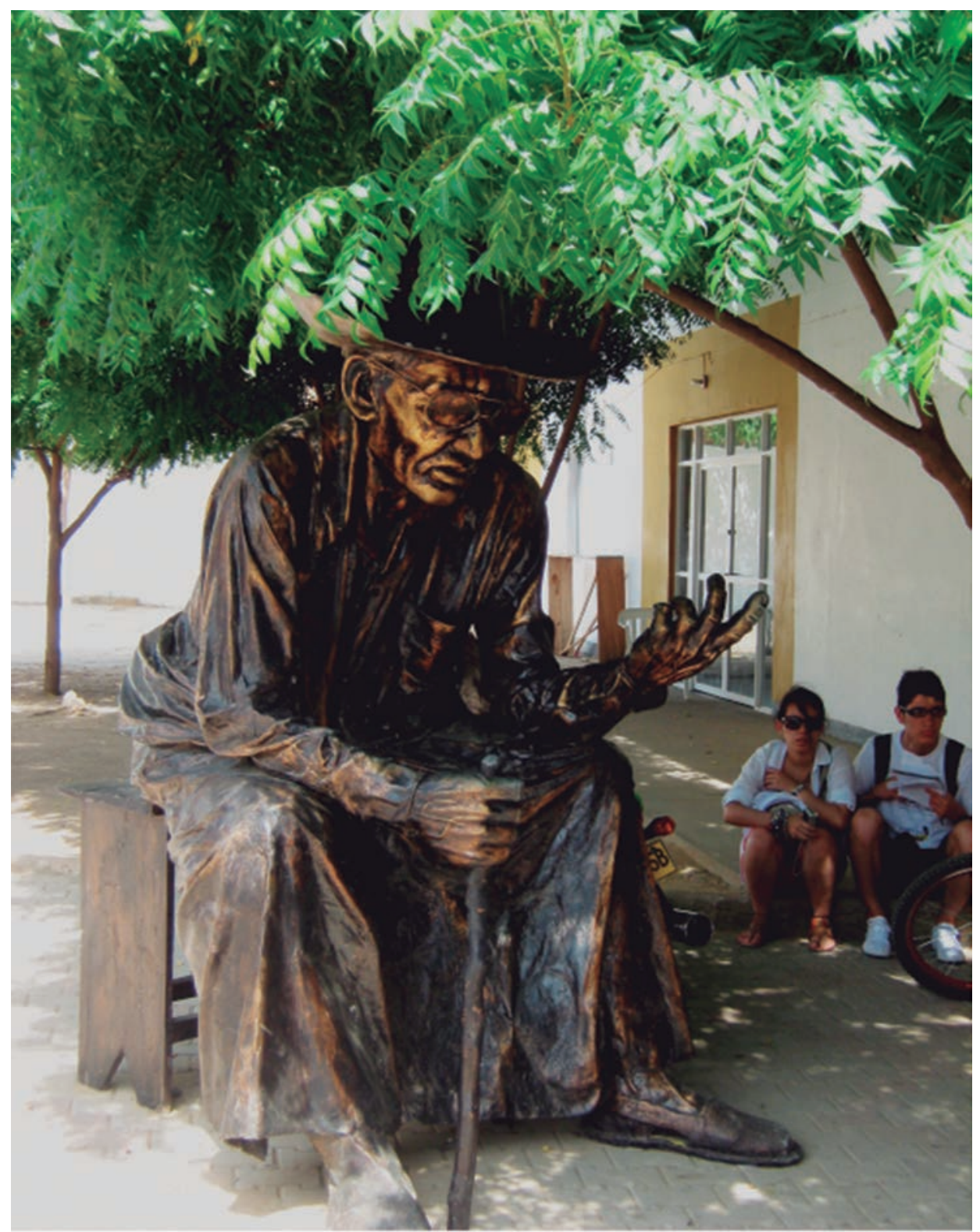

Estos principios de organización social, espiritualidad, lengua materna, concepción de territorio, economía tradicional, se han consignado en el plan especial de salvaguarda del pueblo Wayúu.

Según el DANE 2005, el Municipio de Uribia tiene una población de I 16.674 habitantes, de los cuales el $90.67 \%$ (I05.783), son Wayúu

Las viviendas se caracterizan por estar conformadas por: una enramada, el cuarto de la mujer, la cocina, el baño, el corral de los animales (uno para gallinas, otro para cabras y otro para bovinos), como construcciones aisladas, hechas con materiales del lugar (trupillo, yotojoro, barro, caracolas), y en su cercanía, dada la gran escasez de agua, un amplio depósito para agua lluvia excavado en el piso y llamado jagüey, que a veces se comparte entre varias viviendas; el trupillo es un árbol sembrado al pié de la enramada, está relacionado con el afecto a la casa: (AITPIA: PIA, casa; PIAH, tú); y AITPIA WANEEPIA: permanencia del afecto a la casa. 

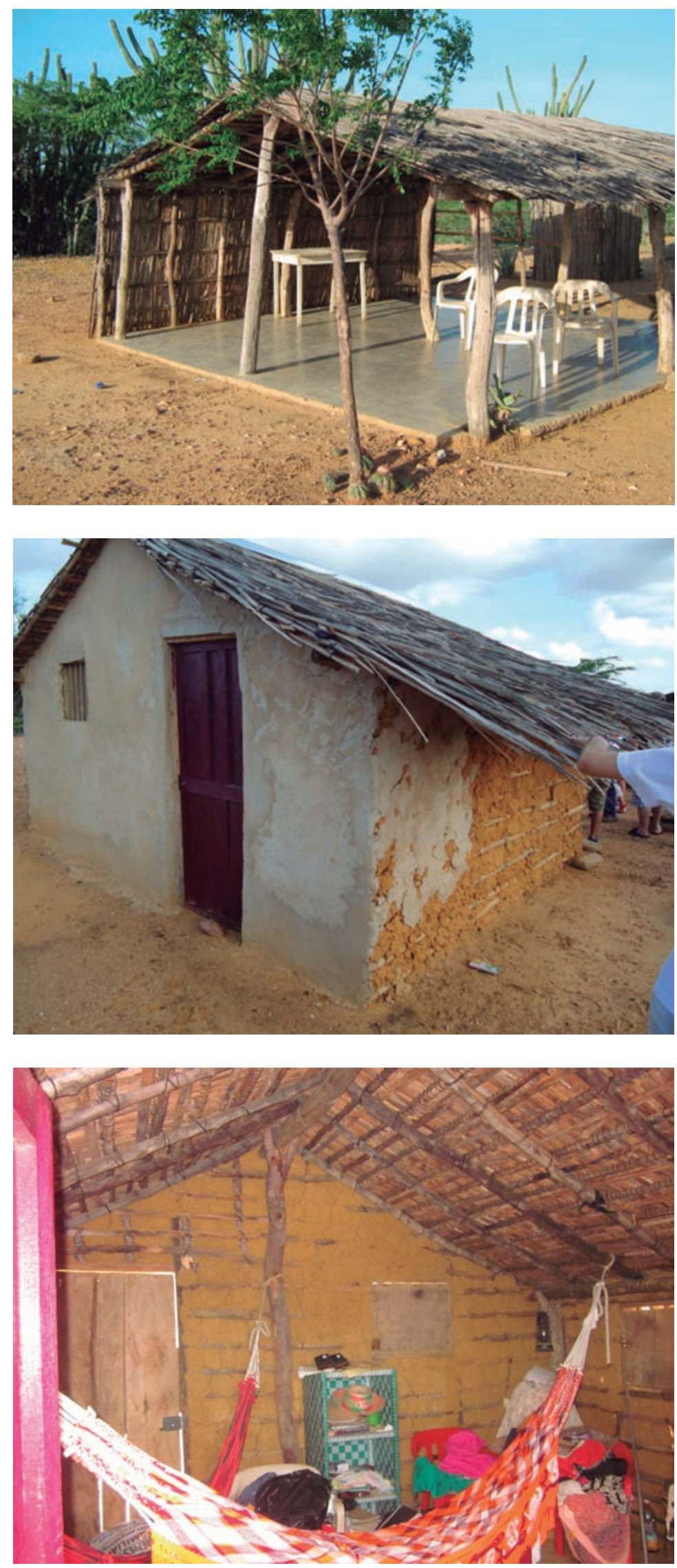

Fotografía 3 La enramada de la vivienda Wayúu

Fuente: fotografia del autor

Fotografía 4 La casa, espacio de la mujer

Fuente: fotografía tomada por el grupo estudiantes USTA

Fotografía 5 Interior de la casa

Fuente: Fotografía tomada por el grupo de estudiantes USTA 


\section{Fotografía 6 Cocina típica}

Fuente: Fotografia del autor

Fotografía 7 Cocina típica con cerramiento en cactus

Fuente: Fotografía del autor

Fotografía 8 La nueva generación heredera Wayúu

Fuente: Fotografía del autor
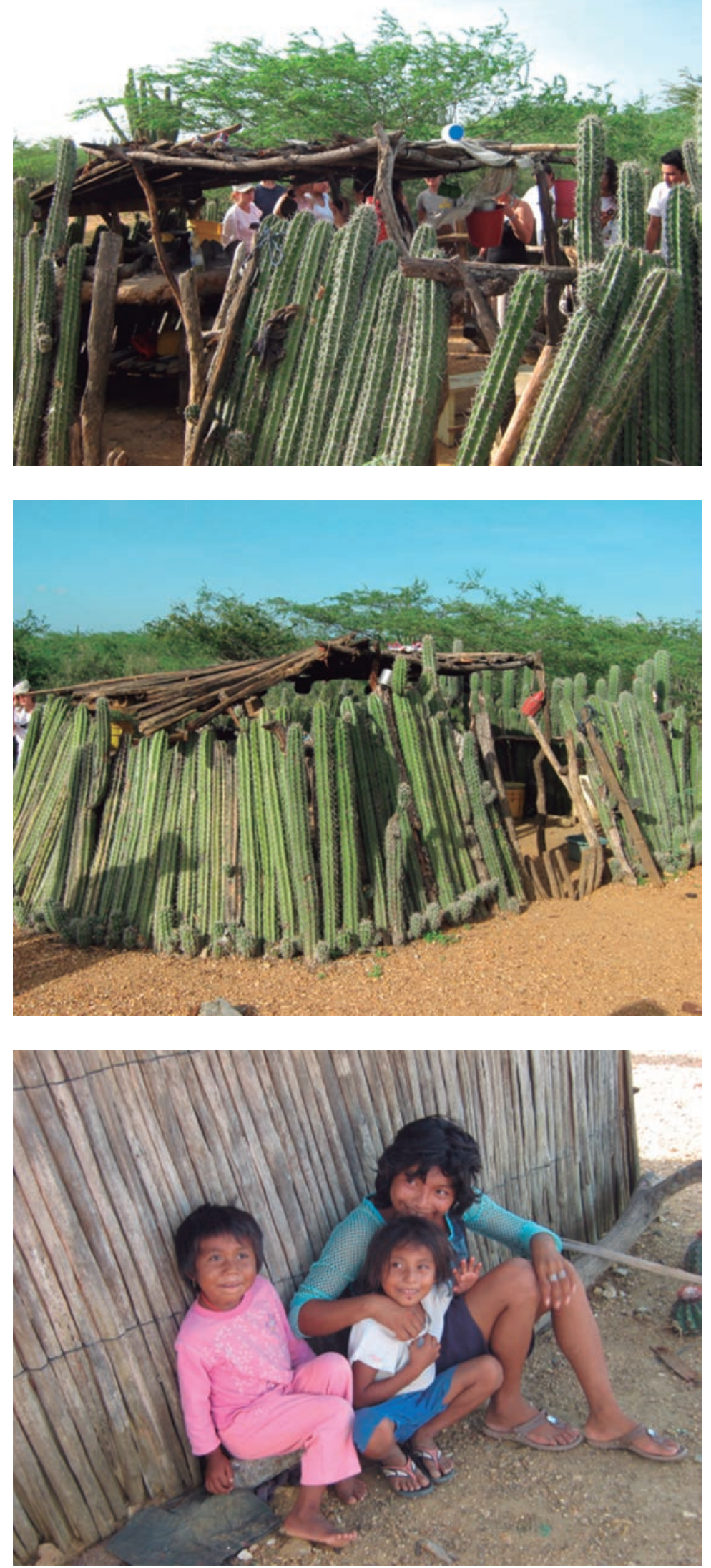
Los Wayúu consideran dentro de su territorio, tres tipos de lugares cargados de simbolismo: los sitios prohibidos, que son lugares que habitan los creadores -cementerios o amuyapa, residencia de sus antepasados-; los sitios encantados, zonas en las que para entrar se debe contar con el permiso respectivo dado por los seres espirituales -serranías y cerros, sabanas, penínsulas y golfos-; y los sitios comunales, para actividades de tipo productivo y de conservación, para ritos de renovación y sanación, o también para sus fiestas de conmemoración -jagüeyes, áreas de pastoreo, cementerios-.

Maleiwa, es el Dios creador de los Wayúu; los esposos generadores de la vida, son Polowi, la mujer, que se asocia con la sequía y los vientos, y Juya es el hombre cazador y errante.

El aspecto económico, se sustenta en la no dependencia de la explotación minera, en la autosostenibilidad, la ley de regalías, la política nacional de seguridad alimentaria y nutricional -CONPES I I 3333 de 2008-, la política del Ministerio de agricultura y desarrollo rural. La actividad económica predominante está basada en la ganadería caprina, artesanías (tejidos que hacen las mujeres), turismo, comercio (perlas, café, sal, electrodomésticos, bebidas alcohólicas, productos ilegales -contrabando, del que se destaca hoy el de la gasolina-), pesca, procesamiento del dividivi, exportación de carbón y gas natural, explotación de sal marina; en territorio venezolano, la explotación del petróleo. Las regalías generadas por la explotación minera, son representativas tanto para el municipio como para el departamento. Sin embargo, la Guajira es uno de los territorios con mayores índices de pobreza. La agricultura se reduce a la subsistencia mínima, con cultivos de maíz, fríjol, yuca, ahuyama, pepino, melón y patilla.

El aspecto ambiental, exige tener en cuenta el clima cálido seco e inhóspito, el régimen de lluvias (que se manifiesta dos veces por año: una primera, es el Juyapu, en los meses de septiembre a diciembre, le sigue una época de sequía, llamada Jemial, que va desde diciembre hasta abril; y la segunda temporada de lluvias, llamada Iwa, para rematar con una larga temporada de sequía desde mayo a septiembre); los recursos naturales (cabros, cactus, yotojoro, trupillo, pesca (pargo, carite, sierra, langosta, jura, bonito, mero, mojarra, raya, caracol, coroncoro) entre otros, sus potencialidades, sus riesgos, sus amenazas. El territorio se caracteriza por tener suelos arenosos y áridos, con vegetación de cactus y matorrales, en la alta Guajira; la media Guajira es semidesértica, con estepas herbáceas y sabanas cubiertas de montes espinosos; y la baja Guajira posee paisajes naturales en los que abundan bosques y pastizales; su privilegiada localización, le permite contar con corrientes de aire aprovechables como fuente de energía eólica, lo mismo que su radiación solar con su potencial como energía solar.

Según crónicas y documentos heredados de la colonia, a principios del siglo XVI, vivieron en la Guajira varios grupos o comunidades diferenciadas, que posteriormente llamaron "guajiros".

Al establecerse los europeos, los grupos indígenas de esa región se dedicaron al pastoreo como forma de vida, y desarrollaron una fuerte y larga resistencia contra las incursiones de la corona española para reducirlos y dominarlos.

Ya en el siglo XX, la explotación petrolera del lago de Maracaibo en Venezuela, y luego la explotación de carbón "El Cerrejón", sumado a la explotación mecanizada de sal marina de Manaure, han venido afectando esta comunidad Wayúu, con procesos de desplazamiento y reducción, que en los últimos años se han agravado con la incursión de grupos armados ilegales que buscan el dominio del territorio dadas sus condiciones de litoral y fronteras. 
Fotografía 9 El baño

Fuente: Fotografía del autor

Fotografía I0 Paisaje típico del territorio Wayúu

Fuente: Fotografía del autor

Fotografía I I Energía Eólica cerca al Cabo de la Vela, de utilización exclusiva para el proyecto de explotación minera "El Cerrejón"

Fuente: Fotografía del autor
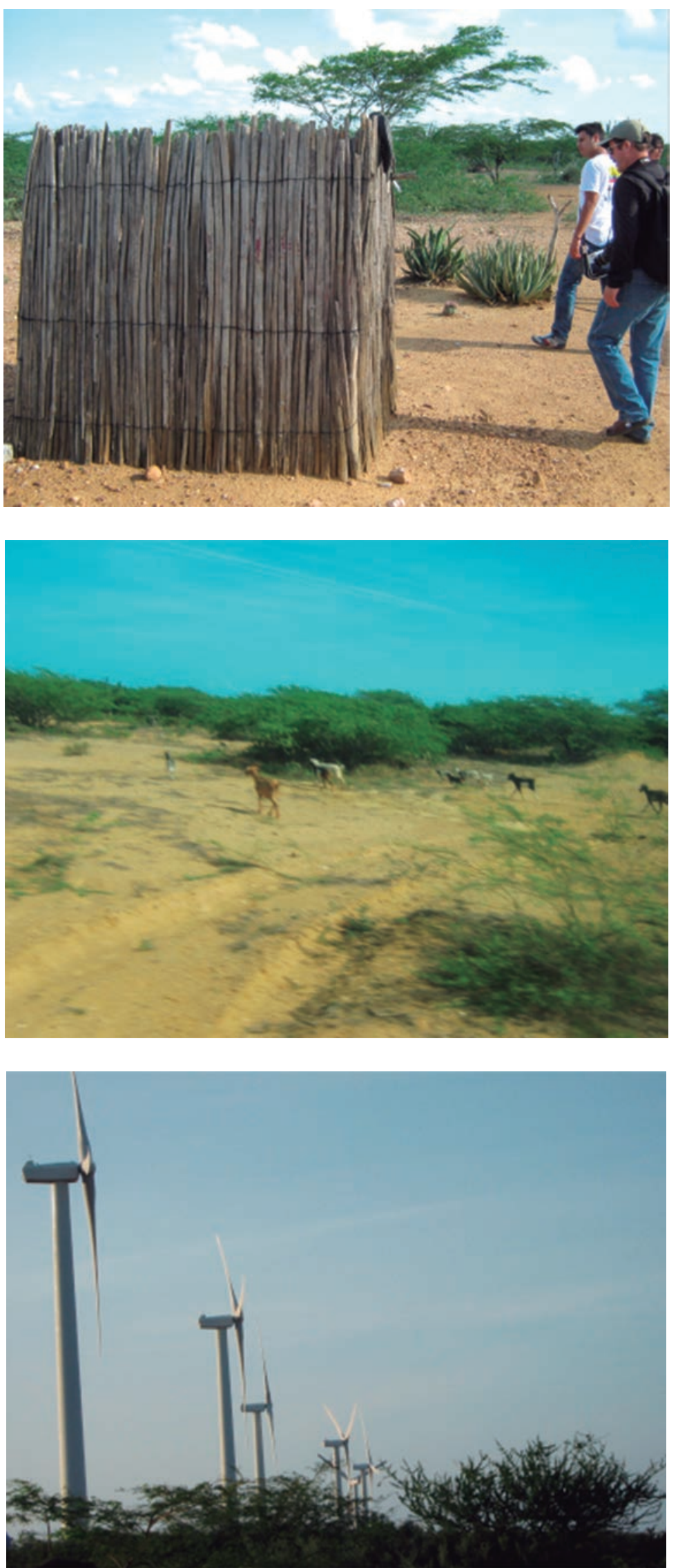


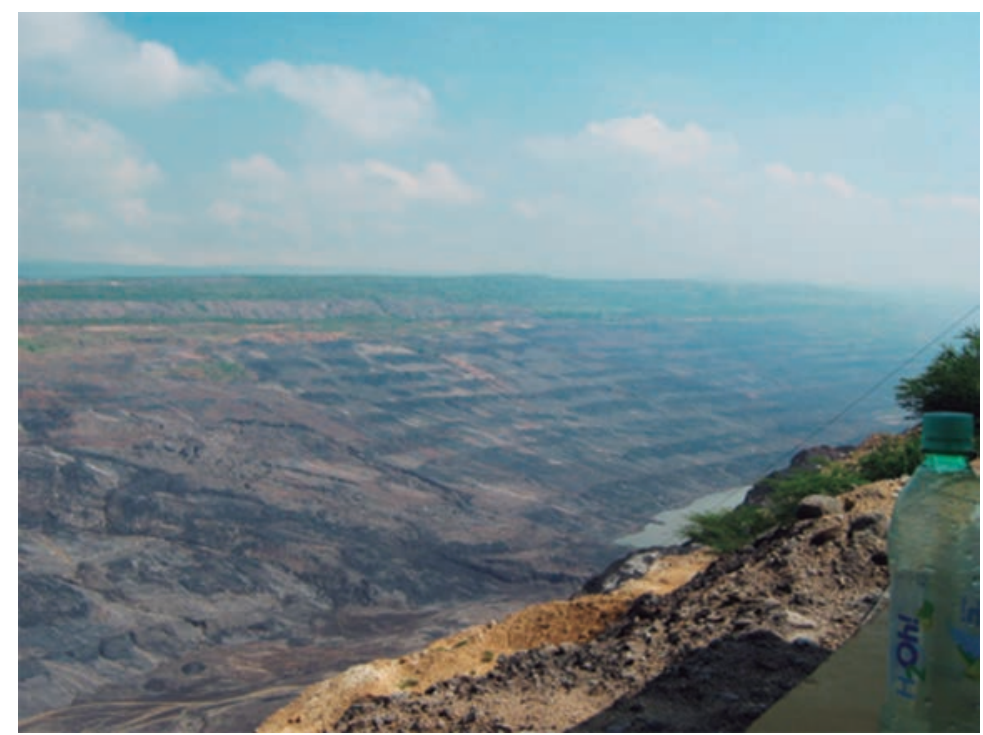

Fotografía 12 No es el Cañón del Chicamocha, es la profundidad... sin los nativos, sin carbón..

Fuente: fotografía del autor

\section{LAS PROPUESTAS}

Presentamos las propuestas, como una experiencia académica en busca de las condiciones de habitabilidad, que se mueve entre el proyecto que demanda investigación, pero así mismo la investigación y su respuesta, el proyecto; orientadas bajo la metodología de la estructura argumentativa.

Los ejercicios aquí planteados por los estudiantes con la dirección de docentes, son ideas y sueños académicos que van en esa búsqueda, pero que para que en la práctica real sean ejecutables con esa visión de dignidad, implica cambios en la estructura y sistema económicos, que no son fáciles de lograr en un sistema donde predomina el interés particular sobre el general, al contrario de lo que la constitución dice.

\section{Primera mención}

La visión prospectiva departamental se fundamenta en

- Crear redes de acueducto en cada municipio de la Guajira, especialmente en aquellos donde el líquido no es abundante, recurso fundamental para una vivienda digna, y generar producción agrícola e incrementar la producción ganadera caprina y bovina

- Fortalecimiento etnoturístico y ecoturístico, mediante la creación de un cordón turístico a lo largo de la costa, en conexión con las serranías de la Macuira, Jarará y Cocinas, y su preservación por sus características ambientales, ecológicas, naturales y su gran significación para la cultura Wayúu

- Aprovechamiento de la luminosidad solar para el cultivo de higuerilla, jatropha, sábila, remolacha azucarera, yuca amarga, para producción de biodiesel, alcohol carburante y productos para la estética en belleza

- Fortalecimiento de la producción que hoy es artesanal, llevada a niveles industriales, como son los curtiembres, en el municipio de San Juan del Cesar; centros de acopio pesquero en el Cabo de la Vela, Puerto Estrella, Manaure y Dibulla, con miras a completar el proyecto de Puerto Brisas 
- Crear un parque ecológico en cercanías a Bahía Hondita

- Explotación de recursos mineros de caliza, yeso, cobre, carbón, oro

En la escala Municipal, en el casco urbano de Uribia, dada su forma radiocéntrica, se propone un crecimiento o expansión del área urbana acorde con los lineamientos planteados. A partir del centro o plaza central, de la que se desprenden las vías de conexión, se propone prolongar tres ejes viales que son los más importantes para la conexión con el territorio, así: uno que continúa hacia el noroccidente con Jojoncito; uno que conecta hacia Maicao al sur oriente; $y$ un tercer eje que conecta con Manaure al occidente.

Figura I Ordenamiento del Municipio Fuente: Suministrada por los autores

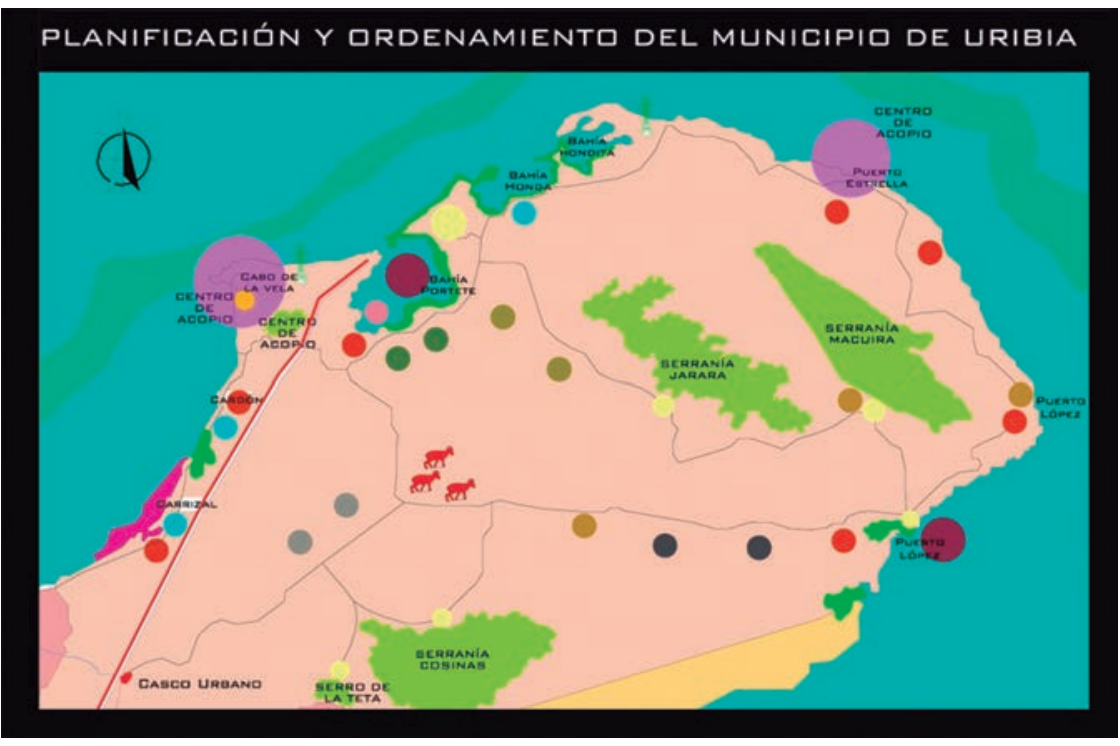

Plano 2. La propuesta Urbana

Fuente: Grupo de estudiantes USTA. Andreína Builes Torres, Gina Paola Camargo, Diana Carolina Padilla, Olfer Meneses

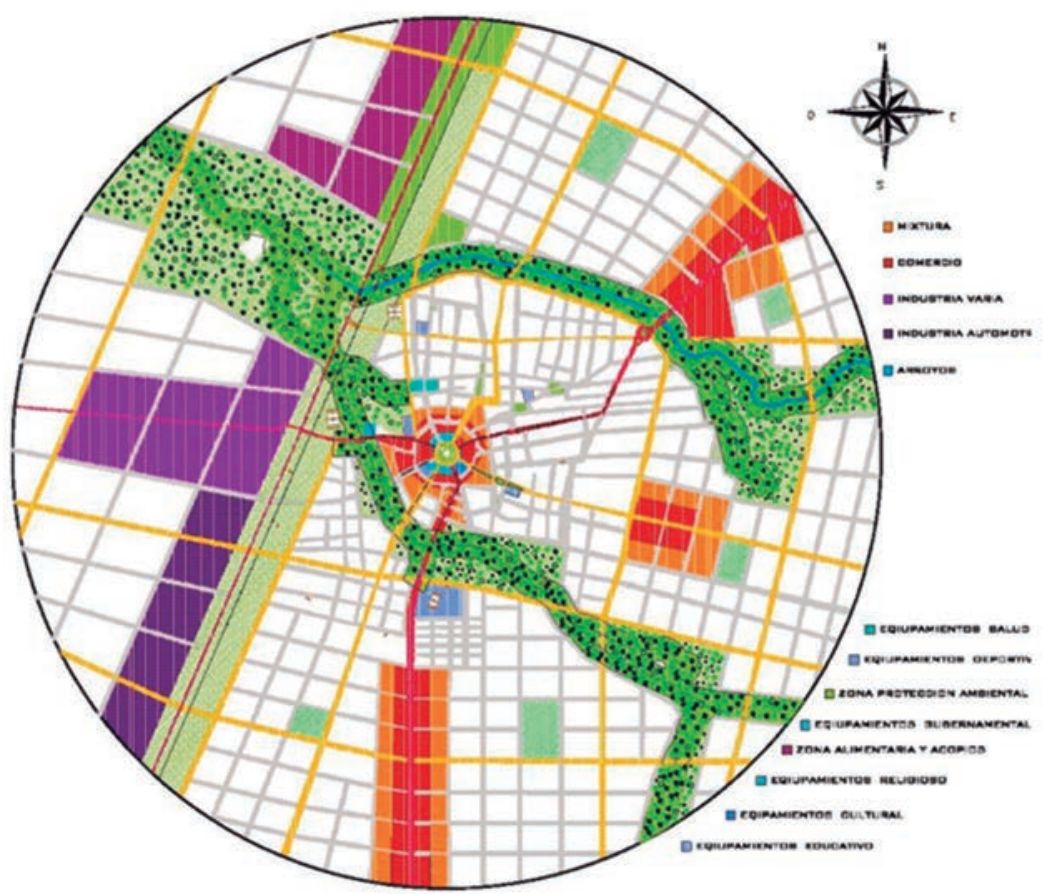


Así, pasar de una estructura radiocéntrica a una regularidad más acorde, que involucre y vincule los barrios periféricos que se han venido construyendo con estructuras ortogonales; en esa configuración se produce una malla de "plato roto", con la característica especial que produce la carretera troncal sur-norte que va hacia el Cabo de la Vela y la vía del ferrocarril que une el Cerrejón con Puerto Bolívar y va paralela a la carretera y pasa por el costado occidental del casco urbano de Uribia, permite proponer al costado occidental de las dos vías aquellos usos y actividades de carácter industrial, de talleres de mantenimiento vehicular y de bodegaje que exigen un tratamiento especial; además de conectar con Manaure directamente.

Los arroyos actuales que rodean el casco urbano deben ser canalizados y tener obras de mitigación de inundaciones con una franja de 70 metros a manera de parque lineal.

En los nuevos desarrollos, las vías principales determinan el uso del suelo, sobre las que se ubica la mayor parte del comercio; entre este comercio y las zonas de vivienda se plantea una mixtura.

Los equipamientos se integran al parque lineal y demás parques al interior de las zonas de vivienda.

La estrategia es que los nuevos barrios permitan una transición entre lo urbano y lo rural, de modo que las agrupaciones en el anillo o borde actual urbano demarcado por los arroyos, tengan esa característica urbana que vaya disminuyendo hacia las afueras, de tal manera que al final los predios tienen más carácter rural, hasta encontrar el ámbito nativo rural Wayúu de rancherías.

La estructura urbana para estos nuevos desarrollos surge de la propuesta urbana general, mediante la articulación entre la zona central y las nuevas áreas a través de una regularización que involucra los barrios ya construidos en trama ortogonal. De ahí que se propone una malla en cuadrícula con el criterio de supermanzanas rodeadas de vías vehiculares, subdivididas en nueve módulos por vías peatonales, en las que cada vivienda dispone de suelo suficiente para el desarrollo de la vida normal del Wayúu; en su centro se localiza un espacio libre para producción comunitaria.

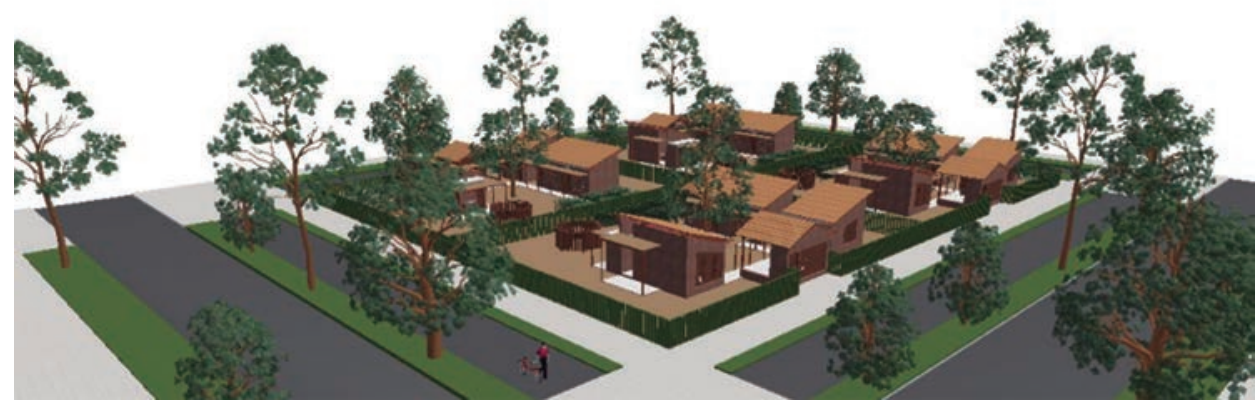

La vivienda está organizada en torno a un espacio libre central que contiene el Trupillo, árbol de gran significación social; en tres de sus costados se distribuyen los componentes espaciales de la vivienda Wayúu, y se enlaza con la huerta familiar de pancoger.
Plano 3 Render o maqueta virtual de las viviendas planteadas

Fuente: Grupo de estudiantes USTA. Andreína Builes Torres, Gina Paola Camargo, Diana Carolina Padilla, Olfer Meneses 
Plano 4 La vivienda y sus componentes

Fuente: Grupo de estudiantes USTA. Andreína Builes Torres, Gina Paola Camargo, Diana Carolina Padilla, Olfer Meneses

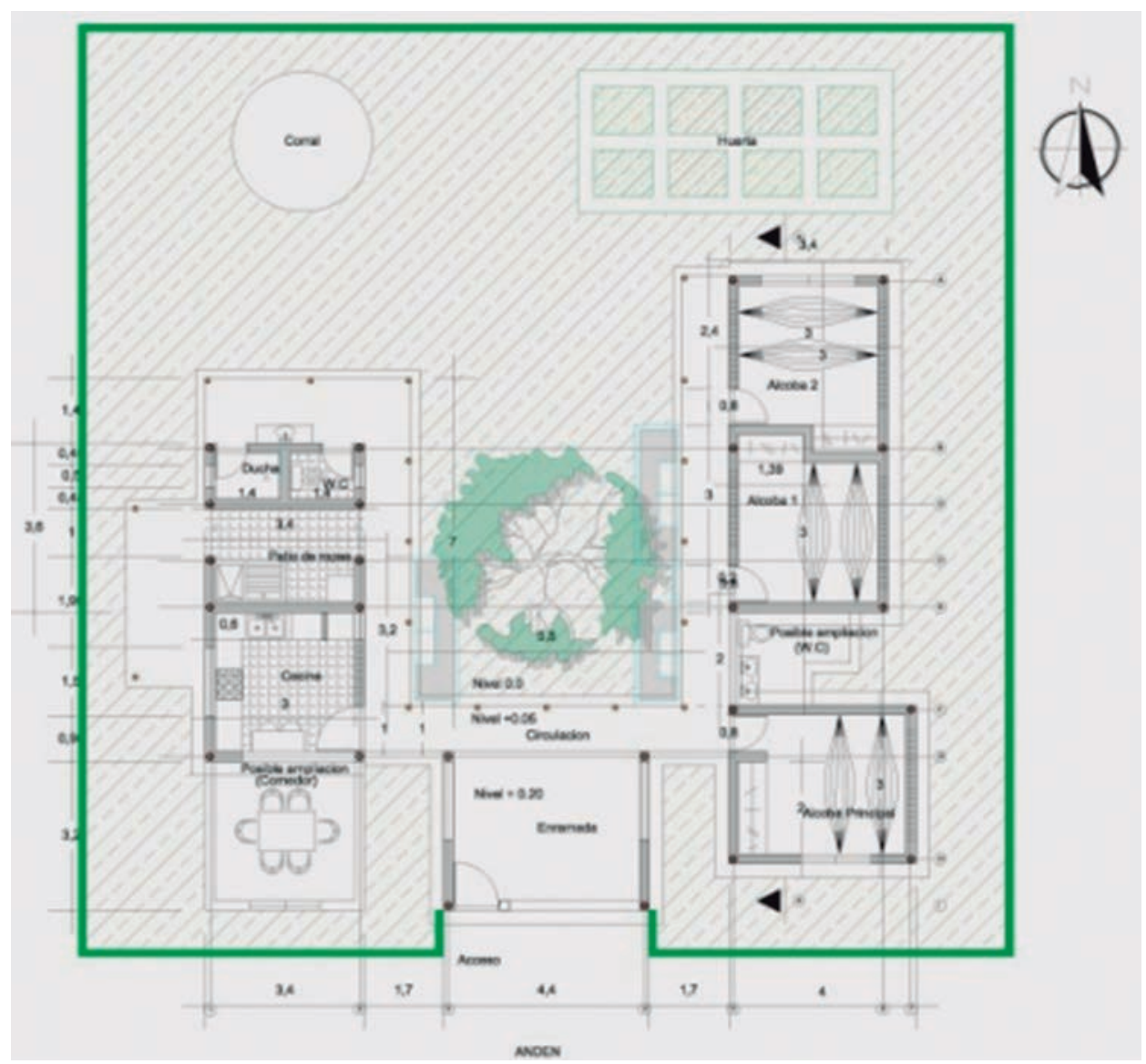

El acceso está determinado por la Enramada, totalmente abierta al espacio central; de un costado están los espacios para dormir, y del otro los servicios de cocina, baño y lavado de ropas; se contemplan futuras ampliaciones como el comedor y baño adicional.

Los materiales a emplear, tienen diferentes alternativas, desde los más tradicionales en el ámbito rural, hasta los materiales nuevos que llegan a Uribia (ladrillos huecos y macizos de arcilla, bloques de cemento, concreto, hierro, aluminio, cerámicos y otros). Los materiales seleccionados son: para muros, bloques de suelo cemento fabricados con máquina $\mathrm{CiN}$ VA-RAM; techos en teja de barro sobre estructura de madera, pisos en cemento afinado, algunos cerramientos, ventanas, puertas y apergolados en yotojoro; los predios tienen cerramientos vivos en cardón.

Estos materiales son los más adecuados desde el punto de vista económico, de estabilidad y de clima, que garantizan la sostenibilidad, además del diseño abierto que permite ventilación y con orientación que controle la asoleación.

\section{Segunda propuesta USTA}

Planteada por los estudiantes de octavo semestre, Mayra Andrea Cepeda, Yexabel Calderón y Wilson Guerrero, se sustenta igualmente en el desarrollo de los potenciales del departamento y del municipio, con las infraestructuras requeridas.

En cuanto a la propuesta urbana, el planteamiento está basado en una trama urbana reticular, a partir de ejes radiales importantes existentes, que establecen el enlace con el territorio; 


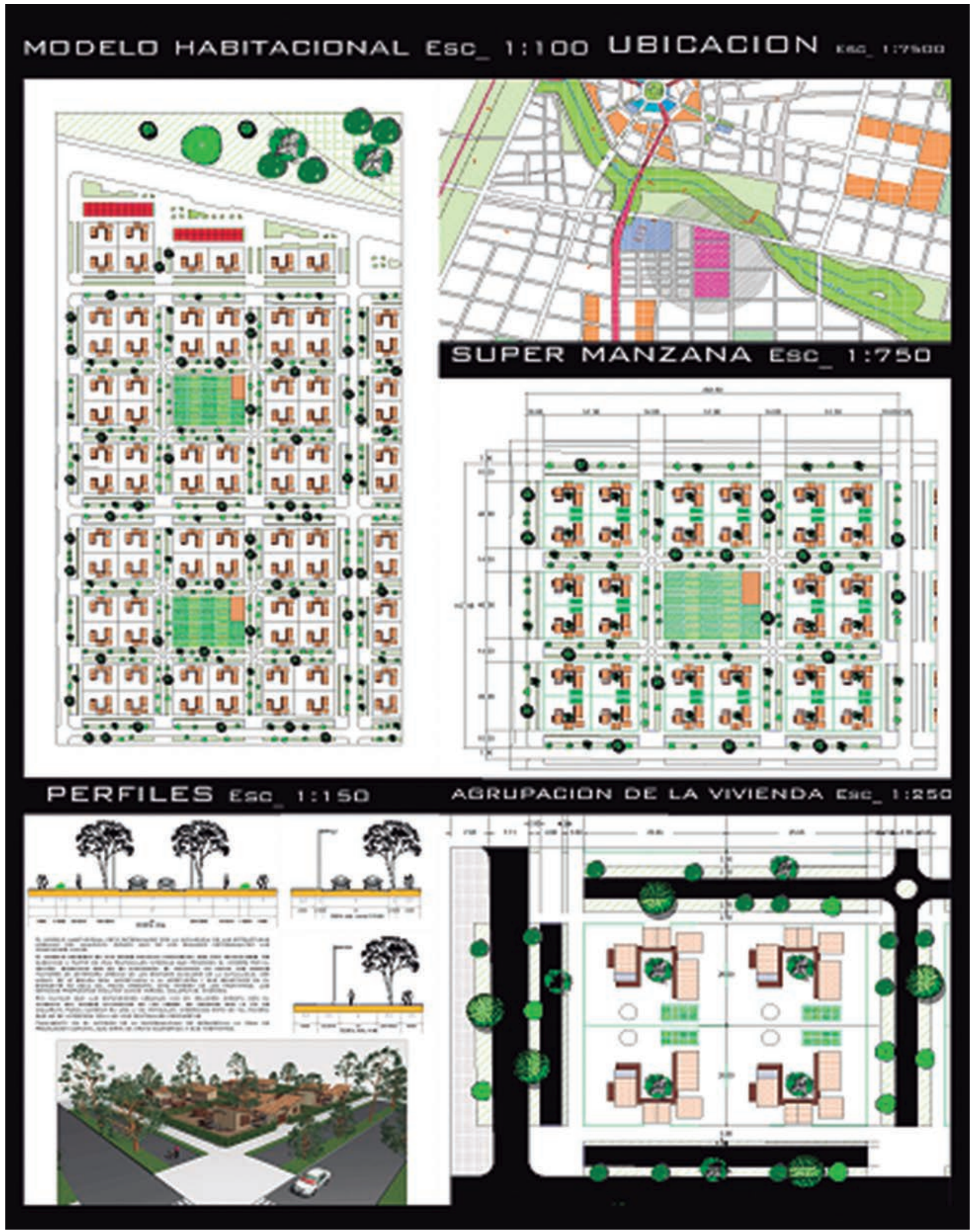

Plano 5. Del conjunto a la supermanzana, a la vivienda

Fuente: Grupo de estudiantes USTA. Andreína Builes Torres, Gina Paola Camargo, Diana Carolina Padilla, Olfer Meneses 
Plano 6 Propuesta urbana y POT Municipal

Fuente: Grupo de estudiantes USTA. Mayra Andrea Cepeda, Yexabel Calderón y Wilson Guerrero
Plano 7 Modelo habitacional y equipamientos en la propuesta urbana

Fuente: Grupo de estudiantes USTA. Mayra Andrea Cepeda, Yexabel Calderón y Wilson Guerrero

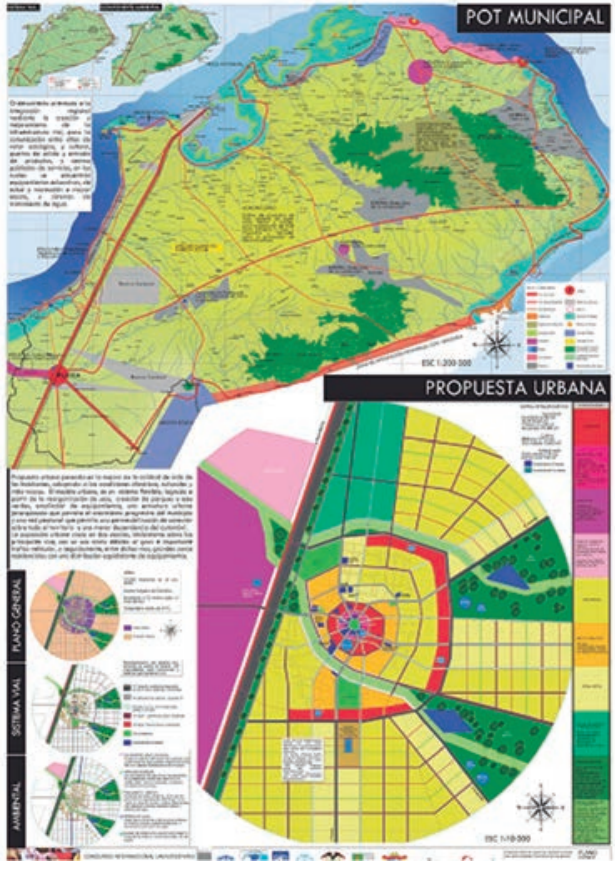

los arroyos secos actuales tienen tratamiento verde que continúa con ensanchamiento en parques dentro de los cuales se insertan equipamientos comunitarios y que permiten la integración entre cada dos sectores residenciales. El costado occidental lateral al ferrocarril y la carretera tendrá uso industrial.

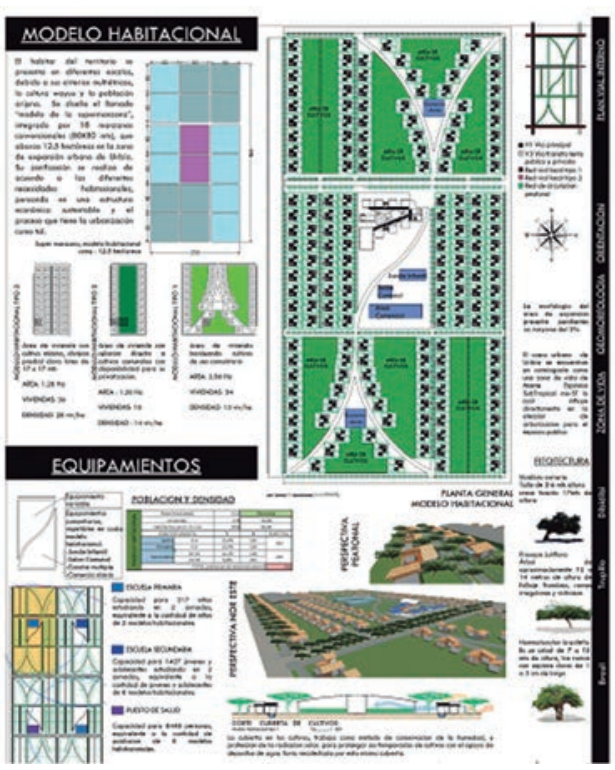

La vivienda se resuelve a partir de una modulación acorde con los componentes espaciales, ordenados en torna a tres costados de un jardín interior relacionado con el espacio libre comunitario para cultivos; los espacios están entrelazados por una circulación cubierta con yotojoro y separados por actividades; el acceso se hace a través de la enramada, pero de forma tangencial; se propuso el predominio de la ventilación cruzada y la orientación que controle el sol; el cerramiento se hace con cardones a manera de cerramiento vivo. La modulación permite dejar espacios libres que luego serán construídos como ampliación. 


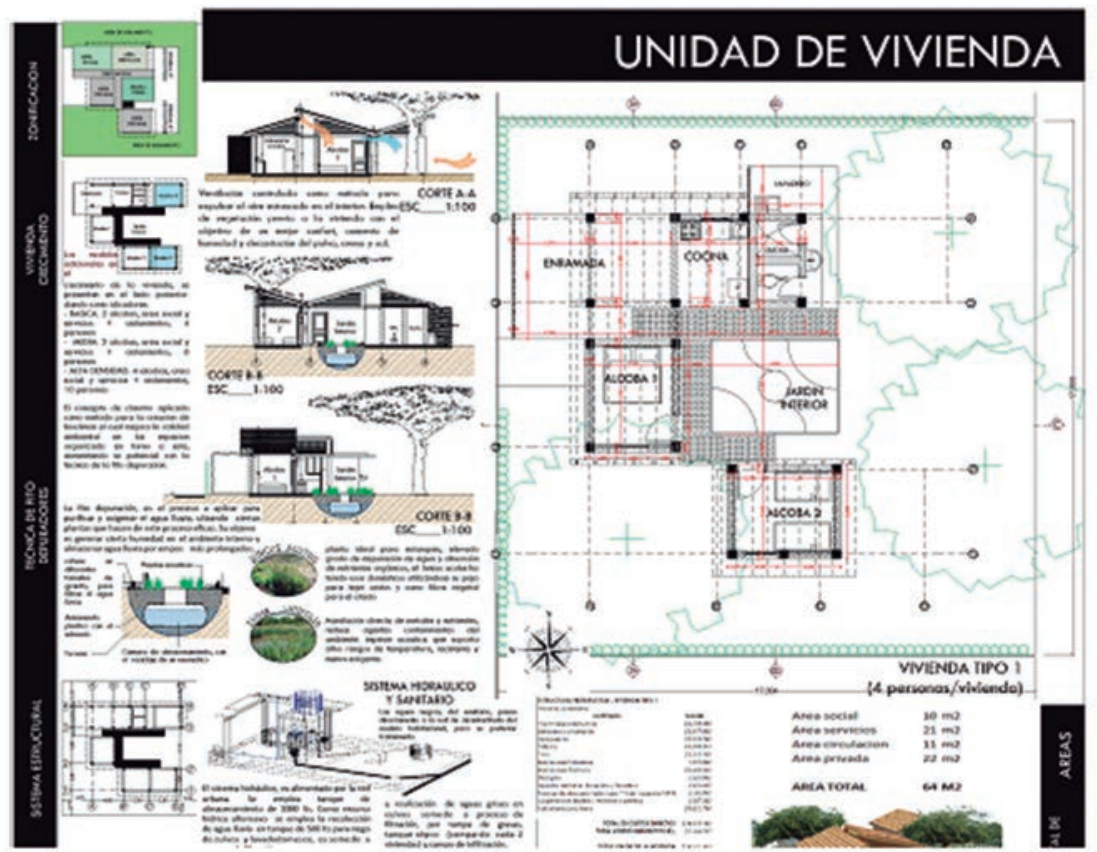

Las viviendas se agrupan en tres modelos de supermanzanas entrelazadas por espacios peatonales interiores, en los que su ubican equipamientos.

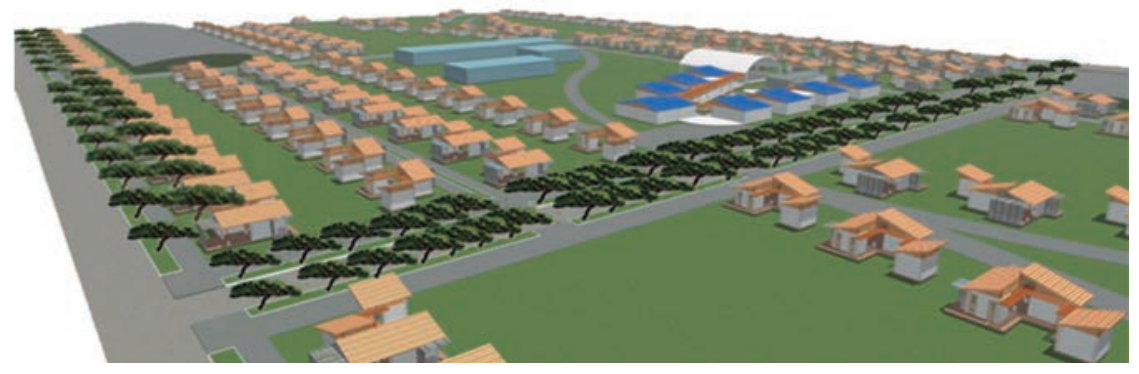

Los materiales empleados son los del lugar, se aprovecha el tipo de suelo existente; muros en bloques de tierra cemento, pisos en cemento afinado, cubierta en teja de barro sobre estructura de madera, cerramiento de algunos espacios con yotojoro (enramada y cocina).

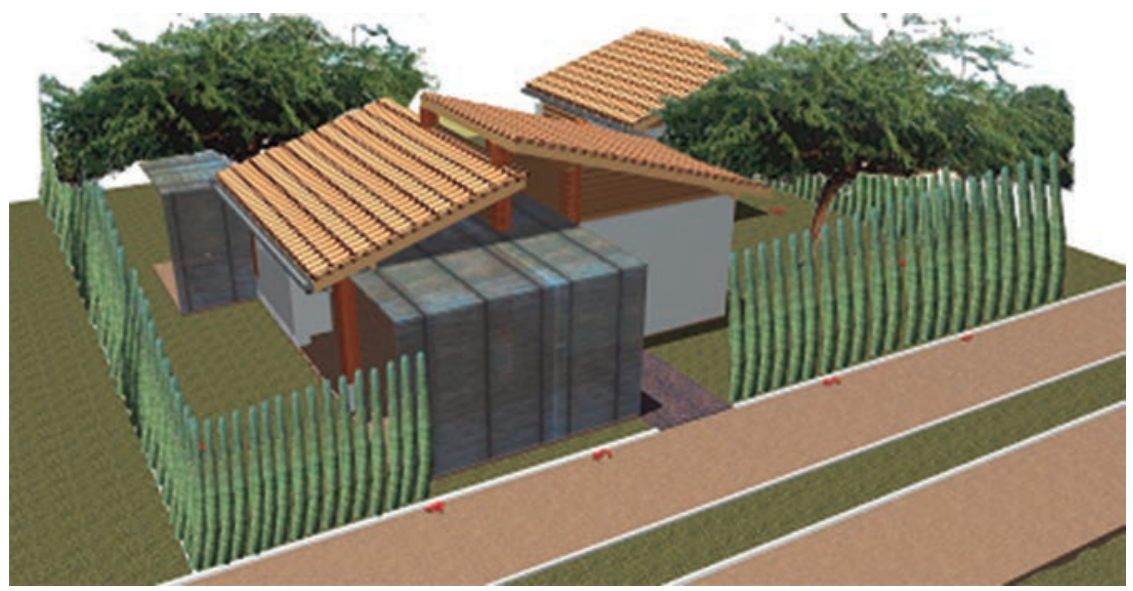

Plano 8. La unidad de vivienda

Fuente: Grupo de estudiantes USTA. Mayra Andrea Cepeda, Yexabel Calderón y Wilson Guerrero

Plano 9 Render o maqueta virtual de vivienda y equipamientos

Fuente: Grupo de estudiantes USTA. Mayro Andrea Cepeda, Yexabel Calderón y Wilson Guerrero

Plano 10 Render o maqueta virtual de la unidad de vivienda

Fuente: Grupo de estudiantes USTA. Mayra Andrea Cepeda, Yexabel Calderón y Wilson Guerrero 


\section{Tercera propuesta USTA}

Plano I/ El diseño urbano

Fuente: Grupo de estudiantes USTA. Claudia Victoria Gambá, Maria Fernanda Martínez y Camilo Corredor

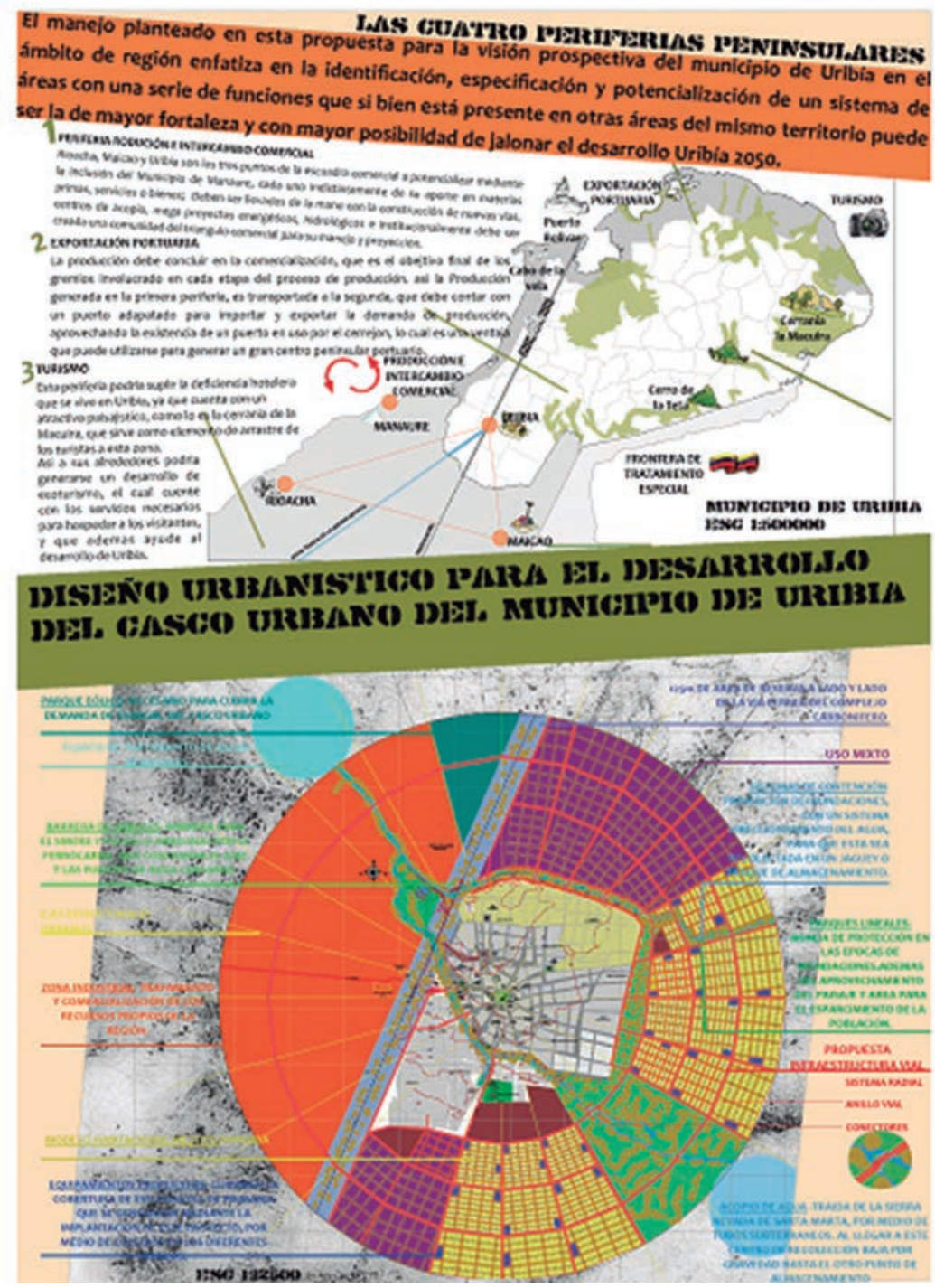

La propuesta parte de la estructura radial actual, rodeada de un anillo verde siguiendo los caños secos actuales, y del cual se desprende un parque entre dos de los ejes radiales hacia el costado sur oriente, hasta el límite de crecimiento previsto. La estructura radial urbana nueva se enlaza con la existente al continuar ejes importantes de conexión con el territorio y anillos viales concéntricos. Las zonas norte y sur occidente, serán de usos mixtos, todo el costado oriental y sur será residencial y contiene el parque mencionado. El costado occidental, al otro lado de la carretera y la vía férrea, tendrá uso industrial, en cuyo extremo norte estará la planta de tratamiento de aguas negras. Habrá zonas de acopio de aguas lluvias para ser tratadas para el consumo. La expansión urbana se prevé en tres fases, una más urbana, la siguiente intermedia entre lo urbano y lo rural y la última que se aproxima a lo rural hasta fundirse con el territorio rural como tal.

La vivienda está planteada como modular y flexible, que permite ser adaptada a diferentes condiciones familiares. Tres esquemas arquitectónicos diferentes con los mismos componentes. Materiales en ladrillos de tierra cemento hechos en el lugar, con la máquina Cinva-ram; madera en la cubierta con amplios aleros que produzcan sombra, yotojoro para cerramientos espaciales según el caso; pisos en cemento afinado. 


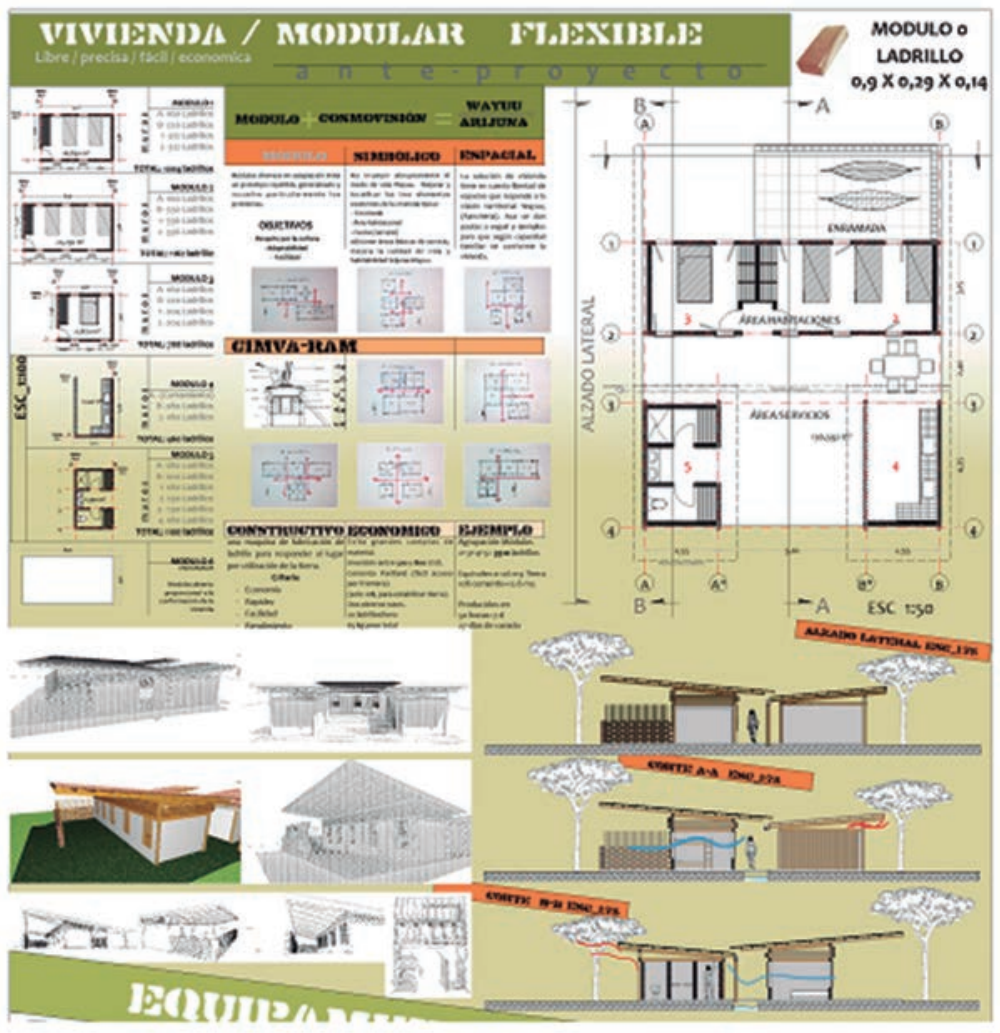

\section{BIBLIOGRAFÍA:}

ARDILA CALDERÓN, Gerardol. "Cuando el progreso se enfrenta a la vida: los Wayúu de la Guajira", en: Diversidad es Riqueza, ensayos sobre la realidad colombiana, Ican, Instituto Colombiano de Cultura y Consejería Presidencial para los Derecho Humanos, Santa Fe de Bogotá, 1992.

Dane. Censo 1993 -Proyección 200 I-.Bogotá, s.f.

Dane. Resultados Preliminares Censo Wayuu, Bogotá, s.f.

GUERRA, Weildler. Los Conflictos Interfamiliares Wayuú, Tesis de Grado, Departamento de Antropología, Universidad de Los Andes, Santa Fe de Bogotá, 1998.

GUERRA, Weildler. La disputa y la palabra, la leyenda la sociedad wayuu. s.f.

JIMÉNEZ, Néstor. Comunidad Indígena Wayuú, Ministerio de Educación Nacional, Fascículo I, Bogotá, s.f.

SANÍN, Patricia. Tesoro Negro, tesoro blanco y MMA. Tesis de grado Departamento de Antropología, Facultad de Ciencias Sociales, Universidad de los Andes, Bogotá, 200 I.

Departamento Nacional de Planeación. Los Pueblos Indígenas de Colombia en el umbral del Nuevo milenio - DNP - s.f.

Departamento Nacional de Planeación. Art 5 I de la Constitución Nacional, "Derecho a la vivienda digna".
Plano 12. Propuesta para una vivienda modular flexible

Fuente: Grupo de Estudiantes USTA. Claudia Victoria Gambá, Maria Fernanda Martínez y Camilo Corredor

\section{247}

